\title{
ANÁLISE DA INFLUÊNCIA DA ESTRATIFICAÇÃO SOBRE PERFIS DE VENTO E TEMPERATURA EM EXPERIMENTOS DE TÚNEL DE VENTO
}

\author{
Giuliano Demarco ${ }^{1}$, Franciano S. Puhales ${ }^{1}$, Felipe D. Costa ${ }^{2}$, Daniel Schuch ${ }^{3,4}$, Amanda F. \\ Faria $^{3}$, Ana C. Avelar ${ }^{3}$, Gilberto Fisch ${ }^{3}$, Otávio C. Acevedo ${ }^{1}$ \\ ${ }^{1}$ Universidade Federal de Santa Maria, ${ }^{2}$ Universidade Federal do Pampa, ${ }^{3}$ Instituto de \\ Aeronáutica e Espaço, ${ }^{4}$ Instituto Tecnológico da Aeronáutica \\ giulianofisico@gmail.com
}

\section{RESUMO}

Este trabalho relata um escoamento estratificado e turbulento, no qual a superfície é mais fria que o ambiente sobre ela. Dessa forma, verifica-se a influência da estratificação sobre os perfis de vento e temperatura.

\section{ABSTRACT}

This paper reports a stratified turbulent flow, in which the surface is colder than the atmosphere about it. Thus, is verified the effect of stratification on the temperature and wind profiles.

\section{INTRODUÇÃO}

O estudo de escoamentos próximo a superfícies cuja temperatura se diferencia da temperatura ambiente vem servindo como desafio (Costa et al., 2011).

A análise de escoamentos em túneis de vento fornece informações sobre o comportamento do escoamento próximo a superfície. Além disso, a modelagem física utilizada nos túneis de vento possui um domínio contínuo, ao contrário do que ocorre na modelagem numérica, onde o domínio analisado é limitado pela capacidade de discretização computacional.

$\mathrm{O}$ ar resfriado em camadas, forma próximo à superfície uma camada estratificada, que se diferencia pelo seu grau de estabilidade. Esse tipo de camada pode ser encontrado, por exemplo, na parte baixa da atmosfera, dentro da camada limite planetária no período noturno ou quando ocorre a passagem de um ciclone extratropical ou frente fria. Para o estudo em questão, estaremos tratando de um escoamento estratificado e turbulento, no qual a superfície fica mais fria que o ambiente sobre ela. Esse tipo de escoamento é amplamente encontrado na natureza, e o seu entendimento é de fundamental importância para o conhecimento das interações entre a camada limite estratificada e o escoamento potencial que se forma logo acima dela; interações essas que contém informações essenciais para o desenvolvimento de modelos numéricos, que tenham como objetivo simular o escoamento atmosférico.

Nesse trabalho, um caso especial desse tipo de escoamento será estudado: escoamento estratificado sobre superfícies com temperaturas uniformes.

\section{MATERIAIS E MÉTODOS}

Os experimentos foram realizados no túnel de vento aerodinâmico subsônico TA-3, situado na Divisão de Aerodinâmica (ALA) do Instituto de Aeronáutica e Espaço (IAE) pertencente ao Departamento de Ciência e Tecnologia Aeroespacial (DCTA). O túnel opera em circuito fechado, velocidade máxima na seção de seção em torno de $35 \mathrm{~m} / \mathrm{s}$ e intensidade turbulenta de aproximadamente $2 \%$, com uma seção de ensaios fechada, do tipo quadrada, 
com dimensões de $500 \mathrm{~mm}$ de altura, $720 \mathrm{~mm}$ de largura e $1200 \mathrm{~mm}$ de comprimento.

Para se obter o efeito de estratificação térmica vertical, construiu-se uma caixa em alumínio e sobre ela uma placa do mesmo material foi sobreposta. Inseriram-se água e gelo dentro da caixa de forma para que a temperatura da placa atingisse uma temperatura de aproximadamente $5{ }^{\circ} \mathrm{C}$. Para o monitoramento de temperatura da placa, utilizou-se um multímetro digital FLUKE SÉRIE 170.

Tratando da velocidade do vento gerada no túnel, um tubo de Pitot Airflow (NPL Type) conectado a um barômetro GE Sensing modelo Druck DPI 610 foi utilizado para aferir as mesmas. Para os processos de aquisição de dados, utilizou-se a anemometria de fioquente, com uma frequência de amostragem de $1 \mathrm{kHz}$ e um tempo de aquisição de dois minutos. Essa foi utilizada para a obtenção da série temporal de velocidade e temperatura do ar, determinando-se posteriormente os valores médios e flutuações.

\section{RESULTADOS E DISCUSSÕES}

As Figuras 1 (a-b) mostram os perfis de velocidade do vento e seus respectivos desvios padrões durante os experimentos realizados. Nos perfis de vento, observa-se que até $50 \mathrm{~mm}$ a camada é sempre turbulenta, porém, para pequenas magnitudes de velocidade $\left(1 \mathrm{~m} \cdot \mathrm{s}^{-1}\right)$, uma diminuição considerável das flutuações bem próximo à superfície são observadas. Outra observação interessante é que ocorre um cisalhamento do vento acima da camada turbulenta. Tais valores são maiores quanto maior a velocidade do vento. Tais situações também são observadas nos trabalhos de Steeneveld et al. (2006) e Costa et al. (2011).
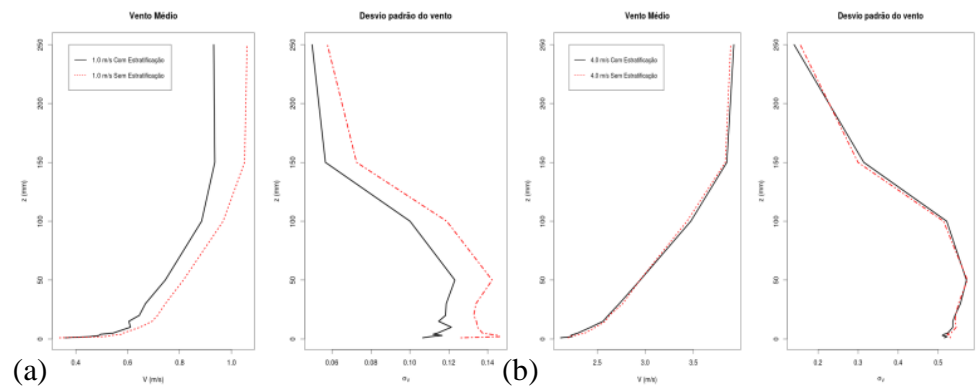

Figura 1 - Perfis de velocidade e respectivos $\sigma v$ para as velocidades de 1 e 4 m/s.

A Figura 2 mostra os perfis de temperatura e seus respectivos desvios padrões. Esses talvez sejam mais elucidativos, quando se verifica a influência da turbulência sobre os perfis de temperatura. É perceptível que, nos cinco experimentos mostrados, a turbulência razoavelmente intensa, influência na estratificação térmica e, para o caso no qual a velocidade é de $5 \mathrm{~m} / \mathrm{s}$ (não mostrada), a estratificação é completamente destruída.

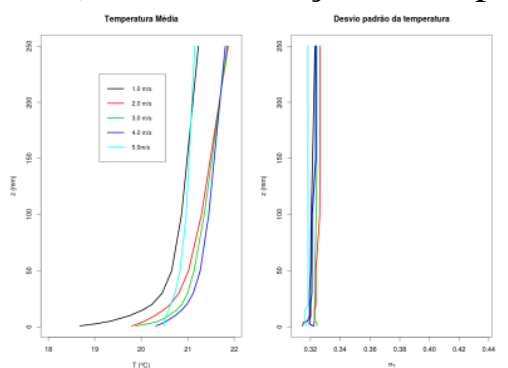

Figura 2 - Perfis de temperatura e seus respectivos $\sigma_{\mathrm{T}}$ para as velocidades de 1, 2, 3, 4 e $5 \mathrm{~m} / \mathrm{s}$. 


\section{CONCLUSÕES}

As análises aqui apresentadas garantem que a estratificação gerada realmente influencia na estabilidade do escoamento, pois se consegue verificar a influência da mesma sobre os valores das flutuações do vento. Da mesma maneira, é possível demonstrar que a turbulência tem influencia sobre a estratificação térmica. Para magnitudes de vento mais intensas, verifica-se que a camada térmica gerada pela estratificação é completamente destruída.

\section{AGRADECIMENTOS}

Os autores do trabalho agradecem à CAPES(PRO-EST.: 2240/2012) e ao CNPQ(Proc. 142712/2009-4 e Projeto Escoamento Atmosférico 559949/2010-3.)

\section{REFERÊNCIAS BIBLIOGRÁFICAS}

Costa, F. D., O. C. Acevedo, J.C.M. Mombach, and G. A. Degrazia, 2011. A Simplified Model for Intermittent Turbulence in the Nocturnal Boundary Layer, 68, 1714-1729.

STEENEVELD, G. J. 2006: Modeling the Evolution of the Atmospheric Boundary Layer Coupled to the Land Surface for Three Contrasting Nights in CASES-99. Journal of the atmospheric sciences, 63, 920-935. 